\title{
1 IL-33 regulates age-dependency of long-term immune dysfunction induced by
}

\section{2 sepsis}

3 David F. Colon ${ }^{1,2}$, Carlos W. Wanderley ${ }^{1,3}$, Walter M. Turato ${ }^{1}$, Vanessa F. Borges ${ }^{1}$, Marcelo

4 Franchin $^{4}$, Fernanda V. S. Castanheira ${ }^{1}$, Daniele Nascimento ${ }^{1,2}$, Douglas Prado ${ }^{1,3}$, Mikhael Haruo

5 Fernandes de Lima ${ }^{1}$, Leila C Volpon ${ }^{5}$, Silvia K. Kavaguti ${ }^{5}$, Fernando Ramalho ${ }^{6}$, Ana P. Carlotti ${ }^{5}$,

6 Fabio Carmona ${ }^{5}$, Bernardo S Franklinn ${ }^{7}$, Jose C. Alves-Filho ${ }^{1,2}$, Fernando Q. Cunha ${ }^{1,3 *}$

$7 \quad{ }^{1}$ Center of Research in Inflammatory Diseases (CRID), Ribeirão Preto Medical School, Departments

8 of ${ }^{2}$ Biochemistry and Immunology and ${ }^{3}$ Pharmacology, University of São Paulo, Ribeirão Preto

9 Brazil. ${ }^{4}$ School of Dentistry, Alfenas Federal University, Alfenas, Brazil. ${ }^{5}$ Pediatrics and ${ }^{6}$ Pathology,

10 University of São Paulo, Ribeirão Preto, Brazil. ${ }^{7}$ Institute of Innate Immunity, Medical Faculty,

11 University of Bonn, 53127 Bonn, NRW, Germany.

13 *Correspondence: Fernando Q Cunha; Center of Research in Inflammatory Diseases (CRID),

14 Ribeirão Preto Medical School, Rua das Paineiras, casa 3; 14049-900, Ribeirao Preto, SP, Brazil.

15 Tel: +55 16 33153324; Email: fdqcunha@,fmrp.usp.br

16 Keywords: pediatric sepsis, sepsis-induced immunosuppression, Tregs, IL-33, M2 macrophages.

17 Run title: Age and long-term sepsis immunosuppression 


\section{Abstract}

22 Sepsis survival in adults is commonly followed by immunosuppression and increased susceptibility

23 to secondary infections. However, the long-term immune consequences of pediatric sepsis are

24 unknown. Here, we compared the frequency of Tregs, the activation of the IL-33/ILC2s axis in M2

25 macrophages, and the DNA methylation of epithelial lung cells from post-septic infant and adult

26 mice. In contrast to adults, infant mice were resistant to secondary infection and did not show

27 impairment in tumour controls upon melanoma challenge. Mechanistically, increased IL-33 levels,

28 Tregs expansion, and activation of ILC2s and M2-macrophages were observed in post-septic adults

29 but not infant mice. Impaired IL-33 production in post-septic infant mice was associated with

30 increased DNA-methylation on lung epithelial cells. Notably, IL-33 treatment boosted the expansion

31 of Tregs and induced immunosuppression in infant mice. Clinically, adults but not pediatric post-

32 septic patients exhibited higher counts of Tregs and sera IL-33 levels. Hence, we describe a crucial

33 and age-dependent role for IL-33 in post-sepsis immunosuppression. 


\section{Introduction}

43 Sepsis is a life-threatening multi-organ dysfunction caused by a dysregulated host response to an

44 infection ${ }^{1}$. Adults that survived a sepsis episode frequently experience long-term

45 immunosuppression, which increases the likelihood of secondary infections by opportunistic

46 pathogens or the development of cancer $2,3,4,5,6$. Despite these serious consequences, little is known

47 about the development of post-sepsis immunosuppression in children. Longitudinal studies analysing

48 the outcomes of survivor pediatric sepsis patients demonstrated that they did not have

49 immunosuppression markers nor impairment in the quality of life after hospital discharge ${ }^{7,8,9}$.

50 In adults, the development of long-term post-sepsis immunosuppression is associated with increased

51 production of anti-inflammatory mediators, such as IL-10, IL-4, or TGF- ${ }^{5,10,11}$; immune system

52 dysfunction ${ }^{5,12}$; epigenetic alterations ${ }^{13,14}$; and expansion of specific cellular populations, including

53 regulatory $\mathrm{T}$ cells (Tregs), $\mathrm{B}$ cells and M2-like macrophage 15, 16, 17, 18 . Indeed, the inhibition of the

54 Tregs suppressive capacity or genetic ablation of foxp3 on T cells significantly reduced the mortality

55 due to secondary infection in sepsis-surviving adult mice ${ }^{15,19}$. Although the main regulator of post-

56 sepsis immunosuppression is undetermined, recently, the alarmin IL-33 emerged as an important

57 "rheostat" for the development of post-septic immunosuppression in adults ${ }^{17}$.

58 IL-33, the latest member of the IL-1 family, is released by non-hematopoietic cells such as lung

59 epithelial cells during injury $20,21,22$. Alveolar epithelial cells have been reported as the major cellular

60 sources of IL-33 23, 24 . IL-33 plays an important role in Th2-associated immune responses. After

61 binding to its receptor (ST2), IL-33 induces the production of the Th2-associated mediators IL-4, IL-

62 5, IL-10, and IL-13 by Th2 lymphocytes, mast cells, type 2 innate lymphoid cells (ILC2) and

63 eosinophils ${ }^{25,26}$. Moreover, IL-33 drives the polarization of alternative-activated macrophages (M2)

64 27. Remarkably, post-septic IL-33 induced expansion of Tregs depends on ILC2s/M2-macrophages

65 17. However, the role of IL-33/ILC2s/M2-macrophages/Tregs axis in sepsis-surviving children 
66 remains unclear. Here, we investigated the long-term immune consequences of sepsis in surviving

67 infants vs adults. Our findings demonstrate that, compared to adults, young mice that survived sepsis

68 do not develop immunosuppression. These findings were recapitulated in sepsis-surviving pediatric

69 patients in whom no Tregs expansion or increase in serum IL-33 levels was observed compared to

70 adults. This study reveals that the long-term immunosuppression after sepsis might be an

71 unappreciated age-dependent phenomenon and suggest that adult and pediatric sepsis-surviving

72 patients require a different treatment approach.

\section{Methods}

\section{Animals}

75 Infant (2 weeks old) and adult (6 weeks old) C57BL/6 mice (wild-type, WT) were obtained from the

76 animal facility of the Ribeirao Preto Medical School of University of São Paulo, São Paulo - Brazil.

77 The animals were housed under standard conditions and received water and food ad libitum. Mice

78 were housed in barrier cages under controlled environmental conditions $(12 / 12 \mathrm{~h}$ of light/dark cycle,

$7955 \% \pm 5 \%$ humidity, $\left.23^{\circ} \mathrm{C}\right)$.

\section{$80 \quad$ Patients}

81 Peripheral blood samples were collected from 21 sepsis-surviving patients (12 children and 9 adults),

82 who were prospectively enrolled in the study after hospital discharge from the Intensive Care Unit of

83 a tertiary-care university hospital at Ribeirão Preto. All patients fulfilled clinical or laboratory criteria

84 for sepsis ${ }^{28}$. Seventeen healthy volunteers (7 children and 12 adults) were recruited as controls.

85 Pediatric disease severity was evaluated by PRISM (Pediatric Risk of Mortality) score and organ

86 dysfunction by PELOD (Pediatric Logistic Organ Dysfunction) score ${ }^{29,}$ 30. The exclusion criteria 
87 included active haematological malignancy or cancer, chronic treatment with steroids,

88 transplantation, HIV infection or advanced cirrhosis.

\section{Ethics approval and consent to participate}

90 Animal studies were reviewed and approved by the Ethics Committee on the Use of Animals

91 (CEUA) of the Ribeirão Preto Medical School, University of Sao Paulo, under protocol number

$92169 / 2011$. The care and treatment of the animals were based on the Guide for the Care and Use of

93 Laboratory Animals ${ }^{31}$. The study was also approved by the Human Subjects Institutional Committee

94 of the Ribeirão Preto Medical School, University of Sao Paulo, under protocol number 4886/2009.

95 Written informed consent was obtained from patients or their parents/guardians/caregivers before

96 enrolment and a blood sample was drawn.

\section{Bacterial culture}

98 The caecal content of an adult C57BL/6 mouse was isolated, filtered through sterile gauze and grown

99 in Brain Heart Infusion (BHI) (BD Diagnostic Systems, Sparks, USA) for 5 days, $37^{\circ} \mathrm{C}$. The bacteria

100 grown in this culture were washed two times with PBS, lyophilized and frozen on aliquots. One vial

101 of bacteria was thawed and grown in a $\mathrm{BHI}$ medium, $37^{\circ} \mathrm{C}$ for 20 hours before each experiment.

102 After two rounds of wash to remove the culture medium, bacteria were resuspended on sterile saline

$103 \quad 0.9 \%$ and the number of bacteria was assessed by absorbance at $600 \mathrm{~nm}$ using a spectrophotometer

104 (Molecular Devices, Sunnyvale, USA). To prepare Pseudomonas aeruginosa suspension, a stock

105 strain isolated in a tertiary-care university hospital of Ribeirão Preto were prepared following the

106 same procedures for caecal bacterial suspension.

107 Experimental design 
108 Infant and adult mice were submitted to sepsis by the intraperitoneal inoculation with $2 \times 10^{8}$

$109 \mathrm{CFU} /$ cavity or $4 \times 10^{8} \mathrm{CFU} /$ cavity of bacterial suspension, respectively. Survival curves were

110 prepared from the data recorded daily and serum biomarkers for organ functions were assayed at

111 regular intervals. To assess the long-term phase of sepsis, animals undergoing sepsis received an

112 intraperitoneal injection of ertapenem sodium (Merck Research Laboratory), $30 \mathrm{mg} / \mathrm{kg}$ to adult mice

113 and $15 \mathrm{mg} / \mathrm{kg}$ to infant mice, beginning $6 \mathrm{~h}$ after sepsis and then every $12 \mathrm{~h}$ up to day 3 . The survival

114 rate was recorded daily for 5 days. At the end of this period, further experiments were performed

115 with the surviving-sepsis mice who were euthanized on day 15 after sepsis induction by

116 ketamine/xylazine overdose (>100 mg/kg, s.c., União Quimica, BR) followed by cervical dislocation.

117 To address the long-term sepsis immuno-consequences, two "double-hit" sepsis models were used:

118 airway bacterial infection and tumor challenge model. For the airway second hit model, infant and

119 adult sepsis-surviving mice were infected on the day 15 or 30 after sepsis induction with a virulent

120 clinical strain of Pseudomonas aeruginosa suspension ( $8 \times 10^{5}$ or $2 \times 10^{6} \mathrm{CFUs} / 40 \mu \mathrm{L}$, respectively).

121 The survival rate was recorded daily for up to 10 days.

122 For a tumor challenge model, melanoma B16 (ATCC) cells lines were cultured in RPMI containing

$12310 \%$ FBS (v/v), penicillin $(100 \mathrm{U} / \mathrm{mL})$ and amphotericin B $(2 \mu \mathrm{g} / \mathrm{mL})$. Before use, cells with $70 \%$ to

$12480 \%$ of confluence were detached with trypsin-EDTA $0.25 \%$ and washed in PBS twice.

125 Subsequently, infant and adult sepsis-surviving mice were subcutaneously inoculated on the day 15

126 after sepsis with the B16 Melanoma cell line $\left(5 \times 10^{4}\right.$ cells/mice $)$. The tumor growth was followed

127 from the day 0 to the day 15 after tumor inoculation. Tumor volumes were calculated according to

128 the formula: tumor volume $\left(\mathrm{mm}^{3}\right)=\mathrm{L} \times \mathrm{W} 2 / 2$, where $\mathrm{L}$ represents the major axis (largest cross-

129 sectional diameter) of the tumor, and $\mathrm{W}$ represents the minor axis. On day 7 after tumor transplant, a

130 tumor density was assessed by IVIS (Xennogen IVIS Spectrum In Vivo Imaging System).

131 Furthermore, on the day 15 after tumor inoculation, animals were euthanized by ketamine/xylazine 
132 overdose (>100 mg/kg, s.c., União Quimica, BR) followed by cervical dislocation and the tumor

133 microenvironment were assessed by FACS.

\section{Bacterial counts}

135 Bacterial counts were determined $6 \mathrm{~h}$ and 1,7 and 15 days after infection, as previously described ${ }^{32}$.

136 Briefly, peritoneal exudate and blood samples were collected, serially diluted, plated on Muller-

137 Hinton agar dishes (Difco Laboratories), and incubated at $37^{\circ} \mathrm{C}$ for $18 \mathrm{~h}$, and $\mathrm{CFU} / \mathrm{ml}$ were recorded.

\section{Glutamate Oxaloacetate Transaminase (GOT) activity}

139 Animals were euthanized $6 \mathrm{~h}$ and 1, 7 and 15 days after infection, and blood samples were collected

140 to measure hepatic damage by assessing GOT activity levels. The assays were performed with a

141 commercial kit (Labtest, Brazil).

\section{Cytokine assays}

143 Cytokine concentrations were measured by ELISA, using antibodies from R\&D Systems according

144 to the manufacturer's instructions. The optical density of the individual samples was measured at 450

145 nm using a spectrophotometer (Spectra Max-250, Molecular Devices, Sunnyvale, CA).

\section{Flow cytometry}

147 Aliquots of cells homogenate $\left(1 \times 10^{6}\right.$ cells per tube $)$ were suspended in buffer containing $2 \%$ FCS in

148 PBS. For surface staining, cells were incubated with specific antibodies to F4/80 (BM8,

149 eBioscience), CD206 (mannose receptor C type 1, MR; MR5D3, AbD Serotec), CD4 (GK1.5,

150 eBioscience; H129.19, BD Biosciences), CD4 (RPA-T4, BD Biosciences, for human), CD45 (30-

151 F11, BD Biosciences), CD11b (M1/70, BioLegend), CD11c (N418, BioLegend; H13, BD

152 Biosciences), T1/St2 (IL-33R, DJ8, MD Biosciences) Lin (145-2C11; RB6-8C5; RA3-6B2; Ter-119; 
$153 \mathrm{M} 1 / 70$, BioLegend), Sca-1 (D7, BioLegend) or the appropriate isotype controls plus FcBlocker for

$15430 \mathrm{~min}$. For transcription factor staining, cells were first stained for surface antigens, then fixed and

155 permeabilized with mouse Foxp3 Buffer Set (BD Biosciences), according to the manufacturer's

156 recommendations. Cells homogenate were then incubated with specific antibodies to FoxP3 (FJK-

$15716 \mathrm{~s}$, eBioscience) or FoxP3 (150D/E4, eBioscience, for human) for 45 min. For intracellular

158 cytokines staining, cells were stimulated for $4 \mathrm{~h}$ with eBioscience ${ }^{\mathrm{TM}}$ Cell Stimulation Cocktail and a

159 protein transport inhibitor-containing Brefeldin (1.5uL/mL StopGolgi; BD Biosciences). Cells were

160 then washed in FACS buffer, fixed immediately in formaldehyde (final concentration 4\%) for 20 min

161 on ice, washed and re-suspended in NP40 0.4\% for $4 \mathrm{~min}$ at room temperature. Cells were washed

162 twice in FACS buffer and stained with an antibody specific for IL-13 (eBio13A, eBioscience) or the

163 appropriate isotype controls. Cells were analysed by FACSCanto using FCS Express V3 (De Novo

164 Software, Los Angeles, CA).

165 Lung Alveolar Epithelial Cells and type 2 Innate Lymphoid Cells immunophenotyping

166 The lung tissue from infant and adult post-septic mice was digested with Liberase TL $(0.2 \mathrm{mg} / \mathrm{mL}$,

167 Roche) and DNase I (0.5 mg / mL, Sigma) for 45 minutes at $37^{\circ} \mathrm{C}$ under rotation. Then, total lung

168 tissue was marked with a lineage antibody (Lin, anti-mouse CD3e, Ly-6G / Ly-6C, CD11b, CD45R /

169 B220, TER-119 PE, Biolegend), anti-EpCAM for 10 minutes at temperature environment. The

170 epithelial alveolar cells were characterized as Lin-EpCAM ${ }^{+}$. For ILC2s characterization, total lung

171 tissue was marked with a lineage antibody (Lin, anti-mouse CD3e, Ly-6G / Ly-6C, CD11b, CD45R /

172 B220, TER-119 PE, Biolegend), anti-CD45 (BD Bioscience) and anti-Sca-1 (BD Bioscience). Data

173 were collected with a FACS Canto II (BD Biosciences) and then were analyzed with FlowJo 10.6.1

174 software (Treestar).

175 In vitro $\mathbf{T}$ cell differentiation 
$176 \mathrm{CD}^{+} \mathrm{T}$ cells were purified from spleen and lymph nodes with anti-CD4 and anti-CD25 microbeads

177 negative selection (Miltenyi Biotech). Isolated cells were activated with plate-bound anti-CD3 (1

$178 \mu \mathrm{g} / \mathrm{mL})$ and soluble anti-CD28 $(1 \mu \mathrm{g} / \mathrm{mL}$, both BD Biosciences $)$ in the presence of Tregs polarizing

179 cytokines. Tregs were polarized with $1 \mathrm{ng} / \mathrm{mL}$ of TGF- $\beta 1$ (R\&D Systems). Cells were cultured for 72

180 hours and collected for flow cytometry analysis.

\section{Macrophage differentiation and polarization}

182 BMDM were differentiated as described previously ${ }^{27}$. Bone marrow cells from infant and adult naïve 183 mice were cultured in the presence of $20 \%$ of L929 cell culture supernatant (v/v) for 7 days. After

184 differentiation, cells were seeded at a density of $1 \times 10^{6}$ cells per well in 12 -well plates and 185 stimulated with LPS (100 ng/mL, M1-like - Sigma-Aldrich), IL4 (10 ng/mL, M2-like, R\&D Systems)

186 or medium (M0 macrophages). After 48 hours, the cells were used for FACS and supernatants for 187 cytokine analysis by ELISA.

\section{Coculture of macrophages with $\mathbf{T}$ cells}

189 Subsets of macrophages (M0, M1 or M2, $5 \times 10^{5}$ per well) were co-cultured for 4 days with effector

$190 \mathrm{CD}^{+} \mathrm{T}$ cells $\left(\mathrm{CD} 4^{+} \mathrm{CD} 25-\mathrm{T}\right.$ cells, $5 \times 10^{5}$ per well) purified from the spleen of naive infant and

191 adult mice, in the presence of IL-2 (10 ng ml-1, R\&D Systems), anti-IL-10 (50 $\mu \mathrm{g} \mathrm{ml-1,} \mathrm{clone}$

192 JES052A5, R\&D Systems) and stimulated with polyclonal anti-CD3 (1 $\mu \mathrm{g} \mathrm{ml-1,} \mathrm{BD} \mathrm{Biosciences)} \mathrm{in}$

193 U-bottom 96-well plates. Cells were then stained for FoxP3 and CD4 and analyzed by FACS.

\section{Total DNA imprinting methylation}

195 Lung Lin- cells of infant and adult sepsis-surviving animals were isolated and the total DNA was

196 extracted using a commercial kit (Wizard® Genomic DNA Purification Kit, Promega) according to

197 the manufacturer's recommendations. Afterwards, the total DNA methylation signature was evaluated 
198 in 100 ng of DNA using the commercial kit (Imprint Methylated DNA Quantification kit, Sigma-

199 Aldrich), according to the manufacturer's recommendations.

\section{Gene expression by real-time PCR}

201 Total RNA from the lung was extracted using TRIZOL reagent (Invitrogen) or RNeasy kit (Qiagen)

202 according to the manufacturer's instructions. Total RNA ( $2 \mu \mathrm{g}$ from tissue and $1900 \mathrm{ng}$ from cells)

203 was reverse-transcribed using high-capacity cDNA RT Kit (Applied Biosystem). A High-Capacity

204 cDNA kit (Life Technologies) was used and results were analyzed by quantitative RT-PCR with a

205 Vii 7 Real-time PCR system (Applied Biosystems). The comparative threshold cycle method and

206 internal control (Gapdh) was used for the normalization of the target genes. Real-time PCR was

207 performed using the following primers: Foxp3, F- TTCTCCAGGACAGACACAACT / R-

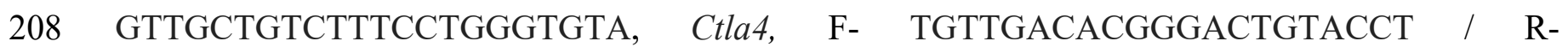

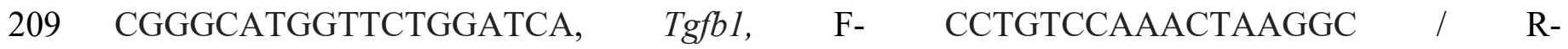

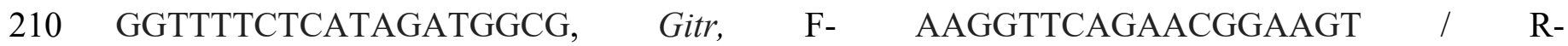

211 GGGTCTCCACAGTGGTAC, and Gapdh, F- GGGTGTGAACCACGAGAAAT / R-

212 CCTTCCACAATGCCAAAGTT.

\section{Western blot analysis}

214 Mice were terminally anesthetized and the lungs were collected. Samples were homogenized in a

215 lysis buffer containing a mixture of proteinase inhibitors (Tris-HCl $50 \mathrm{mM}, \mathrm{pH} 7.4$; NP-40 1\%; Na-

216 deoxycholate $0.25 \%$; $\mathrm{NaCl} 150 \mathrm{mM}$; EDTA $1 \mathrm{mM}$; PMSF $1 \mathrm{mM}$; Aprotinin, leupeptin and pepstatin

$2171 \mu \mathrm{g} / \mathrm{ml})$. Proteins were separated by SDS-polyacrylamide gel electrophoresis and trans-blotted onto

218 nitrocellulose membranes (Amersham Pharmacia Biotech). The membranes were blocked with 5\%

219 dry milk and incubated overnight at $4{ }^{\circ} \mathrm{C}$ with rabbit polyclonal antibody against p-Smad2/3 (1:200;

220 ab272332, Abcam), Smad2/3 (1:200; ab217553, Abcam), p-CREB (1:200; ab32096, Abcam) and 
221 CREB (1:200; ab32515, Abcam). The membranes were incubated with a secondary antibody

222 (Jackson ImmunoResearch). Immunodetection was performed using an enhanced chemiluminescence

223 light-detecting kit (Amersham Pharmacia, Biotech) for $1 \mathrm{~min}$. Optical densitometry was measured

224 following normalization to the control using Scientific Imaging Systems (Image labTM 3.0 software,

225 Biorad Laboratories, Hercules CA).

\section{Statistical analysis}

227 The data (except for the survival curves) are reported as the mean \pm standard error of the mean (SD)

228 of values obtained from at least two independent experiments. The means of different treatments

229 were compared by analysis of variance (ANOVA) followed by Bonferroni's Student's $t$-test for

230 unpaired values. Bacterial counts were analyzed by the Mann-Whitney $U$ test. The survival rate was

231 expressed as the percentage of live animals, and the Mantel-Cox log-rank test was used to determine

232 differences between survival curves. $P<0.05$ was considered significant. All statistical analyses were

233 performed using GraphPad Prism version 9.00 (GraphPad Software, USA). 


\section{Results}

\section{Absence of post-sepsis-induced immunosuppression in infant mice}

243 To assess the immune consequences of sepsis in infants, a "double-hit" sepsis model was used. For

244 this, we induced sepsis in infant ( 2 weeks old) or adult (6 weeks old) mice by intraperitoneal (i.p)

245 injection of bacterial suspension, as previously reported ${ }^{33}$. Mice were treated with the antibiotic

246 ertapenem, beginning $6 \mathrm{~h}$ after sepsis induction and then every $12 \mathrm{~h}$ up to day 3 (Supplemental file

247 1: Figure S1A). As expected, ertapenem significantly reduced the mortality rate of the animals and

248 improved the progressive recovery of body weight (Supplemental file 1: Figure S1B, C).

249 Concentrations of GOT (liver injury) in serum and bacteria loads in blood were also significantly

250 reduced by ertapenem treatment (Supplemental file 1: Figure S1D, E). To address the immune

251 status of sepsis-surviving mice, we administered a non-lethal dose of $P$. aeruginosa, a common post-

252 sepsis opportunistic pathogen 34,35 . For that, infant and adult naïve mice were infected intranasally

253 with different doses of $P$. aeruginosa suspension $\left(10^{5}-10^{6} \mathrm{CFU}\right)$ and the survival rate was recorded.

254 The doses of $8 \times 10^{5} \mathrm{CFU} / 40 \mu \mathrm{l}$ to infants and $2 \times 10^{6} \mathrm{CFU} / 40 \mu \mathrm{l}$ to adult mice that led to $80 \%$ of

255 survival in both groups were selected to be used as the second infection hit (Supplemental file 1:

256 Figure S1F, G). Further, sepsis-surviving mice were submitted to the second hit of $P$. aeruginosa on

257 day 15 or 30 after sepsis induction. In agreement with previous findings ${ }^{15}$, adult mice that survived

258 sepsis become highly susceptible to secondary $P$. aeruginosa infection, indicating the development of

259 post-sepsis immunosuppression. Notably, sepsis-surviving infant mice were resistant to a secondary

$260 P$. aeruginosa infection (Fig. 1A, B) and displayed no changes in the lung bacterial load (Fig. 1C).

261 The results suggest that post-septic infant mice do not develop immunosuppression. Post-sepsis

262 immunosuppression has been described as a key risk factor for the development of lung carcinoma

263 and melanoma growth ${ }^{16,36}$. Therefore, to confirm the post-sepsis immunosuppression, we injected

264 surviving mice with the murine melanoma cell line (B16). Post-sepsis adult mice displayed an 
265 increase in the density and growth of implanted B16 tumors. Confirming the absence of

266 immunosuppression in infant mice, B16-challenged infant mice did not show differences in the tumor

267 growth when compared to the infant sham group (Fig. 1D - F). Additionally, infant post-septic spleen

$268 \mathrm{CD}^{+} \mathrm{T}$ cells proliferation capacity was not compromised after in vitro stimulation with anti-

269 CD3/anti-CD28 compared to adults (Supplemental file 2: Figure S2). Altogether, these results show

270 that sepsis-surviving infant mice do not develop post-sepsis immunosuppression.

271 Lack of Tregs expansion in sepsis-surviving infant mice

272 Because Tregs are a major cellular driver of the post-sepsis immunosuppression in adults $15,16,17,37$,

273 , we sought to assess the in vivo expansion of Tregs population in sepsis-surviving infant mice.

274 Remarkably, in contrast to post-sepsis adults, post-septic infant mice displayed no increase in the 275 spleen Tregs population, as well as no changes in Foxp3 or $T g f b 1$ expression on isolated spleen

276 Tregs, conventional T cells (Tconv) and total spleen tissue (Fig. 2A - D and Supplemental file 3:

277 Figure S3A). Concordantly, we found that the expansion in the frequency of both iTregs (induced

278 regulatory $\mathrm{T}$ cells, $\mathrm{CD}^{+} \mathrm{Foxp}^{+} \mathrm{Neuropilin} 1^{-}$) and $\mathrm{nTregs}$ (natural regulatory $\mathrm{T}$ cells,

$279 \mathrm{CD}^{+}{ }^{+}$oxp $3^{+}$Neuropilin $1^{+}$) did not occur in post-septic infant animals compared to adults

280 (Supplemental file 3: Figure S3B - D). We also observed a significant reduction in the ex vivo

281 proliferation capacity of both total $\mathrm{CD}^{+} \mathrm{T}$ spleen cells and Tregs from post-septic infant mice

282 (Supplemental file 3: Figure S3E, F). To confirm these findings, we carried out the intratumoral

283 Tregs frequency in post-septic bearing breast tumor mice. Consistent with the aforementioned

284 findings, we observed no increase in the frequency of Tregs in the tumor microenvironment of post-

285 septic infant mice compared to the adult counterparts (Fig. $2 \mathbf{E}-\mathbf{F}$ ). Moreover, compared to infant

286 mice in post-septic adult animals we observed a reduced frequency of cell subtypes that are essential

287 for the control of tumor growth (IFN- $\gamma$-producing $\mathrm{CD}^{+}$and $\mathrm{CD}^{+}$cells) ${ }^{39,40,41,42}$ (Fig. 2G - H).

288 Corroborating this, post-septic adult mice presented a higher ratio of Tregs/ IFN- $\gamma$-producing CD8 ${ }^{+}$ 
cells and Tregs/CD4 IFN $^{+}$cells, which indicates a more severely immunosuppressed tumor

microenvironment when compared to the post-septic infant group (Fig. 2I). To investigate the

mechanisms involved in the failure of Tregs expansion, we assessed whether CD4 T cells from infant

mice could have impaired the Tregs differentiation. We stimulated the in vitro Tregs differentiation

of CD4 T cells from adult and infant mice cultured with TGF- 3 . We found that the differentiation to

the regulatory profile $\left(\mathrm{CD}^{+} \mathrm{Foxp}^{+}\right)$was similar in both groups. No differences were found in the

expression of hallmark genes associated with the Tregs profile (Foxp3, Tgfb1, Gitr, Ctla4, and Tigit)

(Supplemental file 4: Figure S4A, B). Validating these findings, we observed that the early

differentiation to the regulatory profile $\left(\mathrm{CD} 4^{+} \mathrm{CD} 25^{\text {hi }} \mathrm{T}\right.$ cells) was similar in both groups

(Supplemental file 4: Figure S4C). We then assessed the early phosphorylation of SMAD2/3 and

CREB, essential transcription factors involved in Tregs stability and differentiation ${ }^{43,44}$, after TGF- $\beta$

stimulation. TGF- $\beta$ increased the expression of activated SMAD2 (p-SMAD2) and CREB (p-CREB)

in a time-dependent manner (Supplemental file 4: Figure S4D), indicating that Tregs differentiation

is an age-independent process. Collectively, these results suggest that the reduced expansion of Tregs

in sepsis-surviving infant mice is independent of the intrinsic fitness of the infant Tregs.

\section{Sepsis does not increase M2-like macrophages profile in post-septic infant mice}

305 To further examine the mechanism of the dampened expansion of Tregs in post-septic infant mice in

macrophages have a particularly important role in post-sepsis immunosuppression through the

showed an increased frequency in peritoneal M2-like macrophages (F4/80 $\left.{ }^{+} \mathrm{CD} 206^{+}\right)$and reduced

310 bacterial killing, the frequency of M2-like macrophages was significantly reduced in post-septic

311 infant mice, with no impairment in the bacterial killing (Fig. 3A, B). Furthermore, the adult post-

312 sepsis immunosuppression triggered the expression of M2 hallmark genes ( $\mathrm{Ym} 1, \mathrm{Mrcl}$ and $\mathrm{Arg} 1)$ in 
313 the peritoneal cells, total lung tissues, and alveolar macrophages. In contrast, no such increased

314 expression was found in post-septic infant mice (Fig. 3C - E). Then, we assessed whether infant

315 mice could have a cell-intrinsic impairment in the M2 polarization. For that, we compared the M2

316 polarization of BMDMs from adult and infant mice in vitro. Consistent with the Tregs findings, we

317 found no impairment in the M2 polarization in infant mice (Fig. 3F and Supplemental file 5: Figure

318 S5A). Moreover, hallmarkM2-associated genes ( $\mathrm{Ym} 1, \mathrm{Mrcl}$ and $\mathrm{Arg} 1$ ) were similarly upregulated in

319 a time-dependent manner in both infant and adult BMDMs in response to IL-4 (Supplemental file 5:

320 Figure S5B). There were also no differences in the production of IGF-1, a tissue damage resolution

321 mediator ${ }^{48}$, as well as in CCL22, a Tregs attracting chemokine ${ }^{49}$ between adult and infant mice

322 (Supplemental file 5: Figure S5C). We then investigated whether M2 infant macrophages are less

323 able to induce Tregs than the adult M2 macrophages. We cocultured M2-like macrophages from

324 infant and adult mice with isolated $\mathrm{CD}^{+} \mathrm{T}$ cells from adult or infant mice, and the Tregs

325 differentiation was assessed. Although adult and infant M2 macrophages were able to induce the

326 Tregs differentiation, this was even more prominent in the presence of infant M2 macrophages (Fig.

327 3G) showing that there is no defect in the ability of M2 macrophages from infant mice to induce

328 Tregs in vitro. Altogether, these findings suggest that events upstream to M2 macrophage

329 polarization and Tregs expansion are involved in the dampened development of post-sepsis

330 immunosuppression in infant mice.

331 Sepsis does not increase the ILC2/IL-33 axis in sepsis-surviving infant mice

332 Recently, the alarmin IL-33, a member of the interleukin (IL)-1 family, has been identified as a major

333 player in the post-sepsis immunosuppression by activating the Tregs/M2-like macrophages axis ${ }^{17}$.

334 We, therefore explored the effect of IL-33 administration on Tregs/M2-like macrophages axis in

335 infant mice. IL-33 administration resulted in a robust expansion of peritoneal M2-like macrophages

336 and spleen Tregs in both infant and adult mice in an IL-33 receptor (ST2)-dependent manner (Fig. 
337 4A, B). Noticeably, compared to the adults, IL-33 treatment led to even a significantly higher

338 expansion of infant $\mathrm{ST}^{+}$Treg cell population (Supplemental file 6: Figure S6) suggesting that

339 there is no impairment in IL-33 responsiveness in infant mice. These findings prompted us to

340 investigate whether the infant post-septic condition affects the IL-33 and type 2 cytokines production.

341 We, therefore measured type 2 cytokines (IL-10 and IL-4) and IL-33 production in the lung tissue

342 and bronchoalveolar lavage (BAL) from sepsis-surviving mice. Lung was selected since epithelial

343 and endothelial lung cells are the major sources of IL-33 23,50 . Consistent with previously reported

344 studies ${ }^{17}$, the post-septic condition resulted in a significant increase in lung IL-33 production and

345 expression as well as an increase of type 2 cytokine production in adult mice. Remarkably, no such

346 increase was evident in post-septic infant mice (Fig. 4C - F). Moreover, we observed that whereas

347 post-septic adult mice showed an increase in BAL IL-33 production accompanied by the reduction in

348 the IL-33 soluble receptor (sST2), the production of BAL IL-33 was significantly reduced in post-

349 septic infant mice with no changes in sST2 production (Supplemental file 7: Figure S7A, B).

350 Pulmonary epithelial cells, especially pulmonary alveolar type II (Lin-EpCAM ${ }^{+}$, have been

351 characterized as the main early and late producers of IL-33 23,24 . Hence, we carried out the

352 expression of $I l 33$ by lung Lin- cells in post-septic mice. Strikingly, we observed only a significant

353 increase of IL33 expression on adult but not infant Lin- cells (Fig. 4G). We then sought to determine

354 the expression of Il33 in alveolar epithelial cells (AECs) isolated from post-septic infant mice. AECs

355 from septic-surviving infant mice showed a reduction in the expression of Il33 when compared to the

356 Sham group (Fig. 4H and Supplemental file 7: Figure S7C). IL-33 production is finely regulated

357 by both molecular and epigenetic events 51, 52. Specifically, in a pathological context, IL-33

358 expression can be regulated by events of acetylation or methylation ${ }^{52,53}$. To further understand the

359 underlying mechanisms involved in the impairment of IL-33 production in post-septic infant mice,

360 we assess the total imprinting DNA methylation of lung Lin- cells from sepsis-surviving infant and

361 adult mice. Strikingly, the post-sepsis condition led to an increase in the total methylation signature 
362 of infant Lin- cells compared to that of the adult mice (Fig. 4I). Importantly, a significant increment

363 in ILC2s frequency, a common downstream IL-33 target population, was only observed in the adult

364 post-septic group but not in the infant post-septic mice (Fig. 4J and Supplemental file 7: Figure

365 S7D). Furthermore, after in vitro stimulation, no impairment in the ILCs function was verified in

366 infant mice assessed by the intracellular production of IL-13 (Fig. 4K). Collectively, these findings

367 suggest that the infant immunosuppression "resistance" might be associated with the impairment of

368 IL-33 production.

\section{Lack of Tregs/IL-33 expansion in sepsis-surviving pediatric patients}

370 Finally, we assessed whether our data from the murine models could be extended to the clinical

371 setting. For that, we investigated the frequency of Tregs in the peripheral blood as well as the serum

372 concentrations of IL-33 in healthy control volunteers and sepsis-surviving adult and pediatric

373 patients. We prospectively included 21 patients (12 children and 9 adults) after hospital discharge in

374 the Emergency Department of a high-complexity hospital. Healthy volunteers (7 healthy children

375 and 12 healthy adults) were included as controls. The baseline demographic and clinical

376 characteristics are summarized in Supplemental file Table 1. PRISM and PELOD scores for

377 pediatric patients and SOFA and APACHE II scores for adult patients during their hospitalization

378 were recorded. Whereas sepsis-surviving adults exhibited a significantly elevated level of Tregs cells

379 compared to healthy controls, the sepsis-surviving infant had a low and similar level of Tregs cells as

380 the healthy infants or adults (Fig. 5A - C). Nevertheless, Tregs cells from the surviving infants

381 retained their suppressive activity (Supplemental file 8: Figure S8). Moreover, consistent with the

382 mouse model, we did not find significant changes in the plasma levels of IL-33 of post-septic

383 pediatric patients (Fig. 5D). These data, therefore demonstrate that the reduced level of IL-33

384 production in infant mice and pediatric sepsis patients could be responsible for the reduced level of 
385 Tregs cells and the resistance of long-term immune suppression that is often observed in adult sepsis

386 individuals.

\section{Discussion}

388 Several studies have described the post-sepsis immunosuppression syndrome in adults (Cavassani et

389 al., 2010; Hotchkiss et al., 2013; Monneret et al., 2003; Nascimento et al., 2010; Nascimento et al.,

390 2017). However, such immune consequences of sepsis are not significant in children. Concordantly,

391 in comparison to non-survivors, sepsis-surviving pediatric patients did not show leukopenia, an

392 outcome accompanied by reduction of IL-10 expression in monocytes (Hall et al., 2007; Hall et al.,

393 2011). Furthermore, neonate mice with early-onset sepsis did not have an increased frequency for

394 the development of late-onset sepsis immunosuppression (Wynn et al., 2013). Moreover, whereas

395 sepsis-surviving adult patients have up to five times the risk of acquiring a secondary infection after

396 hospital discharge (Cuthbertson et al., 2010), the infant post-septic patients have a low risk of

397 secondary infection (Morrison et al., 2002). The mechanisms for this differential immune suppression

398 between adults and infants recovering from sepsis are largely unknown.

399 Data reported here demonstrate that, compared to the adults, sepsis-surviving infant mice do not

400 develop post-sepsis immunosuppression. Specifically, post-septic infant mice are resistant to

401 secondary bacterial infections. Notably, we found that this is associated with a failure of Tregs

402 expansion as well as reduced activation of M2-like macrophages/IL-33 axis. Moreover, the post-

403 septic infant condition was associated with an increase in DNA methylation in lung Lin- cells,

404 leading to reduced IL-33 production compared with those from the adult counterparts. Consistent

405 with this observation, treatment of infant mice with exogenous IL-33 led to a higher expansion of the

406 Tregs population and immunosuppression, demonstrating that the decreased IL-33 production in

407 infant mice is essential for their resistance to post-sepsis immunosuppression. The clinical relevance 
408 of our findings was supported by the observation that sepsis-surviving pediatric patients exhibit

409 neither systemic Tregs expansion nor increased serum IL-33 levels compared to adult counterparts.

410 Expansion of cord blood Tregs population in neonatal patients with early-onset sepsis (12 days old)

411 has been reported to be inversely correlated with the severity of the disease (Timperi et al., 2016).

412 Likewise, the expansion of the Tregs population has been reported in newborn mice (five to seven

413 days old) $24 \mathrm{~h}$ after sepsis induction (Wynn et al., 2007). The discrepancy between these reports and

414 our current finding is likely due to the difference in experimental protocols used. Unlike our

415 experimental system, most of these studies used umbilical cord blood and included acute sepsis

416 patients instead of sepsis-surviving patients. It is noteworthy that Tregs in vitro differentiation and

417 CD4 T cells TGF- $\beta$ responsiveness are not compromised by age, suggesting that the failure of Tregs

418 expansion in vivo does not rely on failure in infants Tregs fitness. Furthermore, the expansion of M2

419 macrophages in adult post-septic mice was not observed in infants. However, similarly to Tregs, the

420 differentiation of M2 macrophages in vitro was not compromised in infant mice. These results

421 suggest that the mechanisms that drive the M2/Treg axis could be upstream of these cells.

422 Recently, our group demonstrated the role of IL-33 as a key regulator of post-sepsis

423 immunosuppression in adult mice (Nascimento et al., 2017). IL-33 is constitutively produced mainly

424 by epithelial and endothelial cells and acts as an endogenous danger signal, or alarmin, in response to

425 tissue damage (Cayrol and Girard, 2014; Liew et al., 2010; Smith, 2010). IL-33 levels remain

426 elevated in the lung of sepsis-surviving adult mice, leading to the expansion and activation of ILCs

427 populations, which orchestrates a macrophage alternative reprogramming toward an M2-like profile,

428 type 2 cytokines production and expansion of Tregs population (Nascimento et al., 2017). In our

429 study, we observed that the M2-like reprogramming, type 2 cytokines production (such as IL-4), and

430 especially IL-33 production in sepsis-surviving infant mice was not increased, suggesting an

431 unrecognized age-dependent regulation of IL-33 production in a post-septic state. The expression of 
432 IL-33 is finely regulated by epigenetic events (Polumuri et al., 2012; Zhang et al., 2014) (Larouche et

433 al., 2018; Zhang et al., 2014) thus we addressed the total DNA methylation imprinting in post-septic

434 infant mice. Compared with adults, lung Lin- cells from post-septic infant mice show a higher total

435 methylation signature, which might be related to the impairment of IL-33 production. The

436 mechanism by which methylation signature might regulate IL-33 production during pediatric sepsis

437 warrants further investigation. Taken together, our findings reveal that post-sepsis

438 immunosuppression is an age-dependent phenomenon. In this context, the differential production of

439 IL-33 has an important implication for the treatment of adult and pediatric post-sepsis 440 immunosuppression.

\section{Abbreviations}

442 Tregs, Regulatory T cells. BMDM, Bone marrow-derived macrophages. AECs, Alveolar Epithelial 443 Cells. GOT, Glutamic Oxaloacetic Transaminase. ILC2s, Type 2 innate lymphoid cells.

\section{Declarations}

\section{Consent for publication}

446 Not applicable

\section{Competing interests}

448 The authors declare that they have no competing interests.

\section{$449 \quad$ Funding}

450 The research received funding from the São Paulo Research Foundation (FAPESP n. ${ }^{\circ}$ 2013/08216-2),

451 the Center for Research in Inflammatory Disease (CRID 2011/19670-0), the University of São Paulo 
452 NAP-DIN (11.1.21625.01.0), the Conselho Nacional de Pesquisa e Desenvolvimento Tecnológico,

$453 \mathrm{CNPq}$ ) and the Coordenação de Aperfeiçoamento de Pessoal de Nível Superior (CAPES). This study

454 was also supported by intramural funding from the Medical Faculty of the University of Bonn to

455 BSF. BSF is further supported by grants from the European Research Council (PLAT-IL-1, 714175);

456 and Germany's Excellence Strategy (EXC 2151 - 390873048) from the Deutsche

457 Forschungsgemeinschaft (DFG, German Research Foundation).

458 Authors' contributions

459 Conceived and designed the experiments: DC, CW, WT, VB, FV, DN, JA, BSF and FC. Performed 460 the experiments: DC, CW, WT, VB, MF, FV, DN, DP and MHL. Analyzed the data: DC, CW, FV, 461 JA and FC. Contributed reagents/materials/analysis tools: FC. Wrote/revised the paper: DC, CW, 462 WT, JA, BSF and FC.

\section{Acknowledgements}

464 We are grateful to Ieda dos Santos, Marco Antônio, Sergio Rosa, Vagner Jesus, Ana Kátia dos Santos

465 and Giuliana Bertozi for technical assistance. We are also grateful to Nathalia Sofia Rosero and

466 Cornelia Rohland for their technical assistance. We also thank the FACS Core Facility of the Medical

467 Faculty at the University of Bonn for providing help, services, and devices funded by the Deutsche

468 Forschungsgemeinschaft (DFG, German Research 764 Foundation, project number 216372545). 


\section{Figure legends}

474 FIGURE 1. Absence of post-sepsis-induced immunosuppression in infant mice. Infant and adult

475 mice were intraperitoneally injected with $2 \times 10^{8}$ and $4 \times 10^{8}$ colony-forming units (CFU) of cecum

476 bacteria, respectively, and after six hours, the ertapenem antibiotic therapy (Abx, $15 \mathrm{mg} / \mathrm{kg}$ for infant

477 and $30 \mathrm{mg} / \mathrm{kg}$ for adults) was initiated and maintained for 3 days, via intraperitoneal (i.p) twice a day.

478 On days 15 (A) or 30 (B), the surviving mice were submitted to the second hit with an intranasal

479 injection of $P$. aeruginosa, $8 \times 10^{5} \mathrm{CFU}$ for infant and $2 \times 10^{6} \mathrm{CFU}$ for adults, and the survival

480 percentage was calculated with the data recorded daily for 10 days. (C) The logarithm of CFU per

481 lung (Log CFU/lung) was determined by seeding the bronchoalveolar lavage (BAL) collected $12 \mathrm{~h}$

482 after $P$. aeruginosa infection in the 15 days sepsis-surviving (Sepsis $15 \mathrm{~d}$ ) mice. We also submitted the

483 Sepsis $15 \mathrm{~d}$ mice to B16 melanoma cells subcutaneous inoculation ( $5 \times 10^{4}$ cells $/$ mice $)$ and, after 7 days,

484 the tumor density (D) was evaluated by in vivo imaging system (IVIS) and the average radiance was

485 expressed in $10^{4}$ photons per second per square centimeter per steradian $(\mathrm{p} / \mathrm{sec} / \mathrm{cm} 2 / \mathrm{sr})$ (E). The

486 tumor volume (F) in cubic millimeters $(\mathrm{mm} 3)$ was also evaluated daily from day 10 to day 15 after

487 tumoral cells challenging. Data are mean $\pm \mathrm{SD}, \mathrm{n}=6-8$ per group and are representative of 2-3

488 independent experiments. ${ }^{*} p<0.5$ and ${ }^{* *} p<0.01$ (A - B, Mantel-Cox log-rank test; C - F, one way-

489 ANOVA, Bonferroni’s).

490 FIGURE 2. Lack of Treg expansion in sepsis-surviving infant mice. Infant and adult mice were

491 intraperitoneally injected with $2 \times 10^{8}$ and $4 \times 10^{8}$ colony-forming units (CFU) of cecum bacteria,

492 respectively, and after six hours, the ertapenem antibiotic therapy $(\mathrm{Abx}, 15 \mathrm{mg} / \mathrm{kg}$ for infant and 30

$493 \mathrm{mg} / \mathrm{kg}$ for adults) was initiated and maintained for 3 days, via intraperitoneal (i.p) twice a day. The

494 frequency in percentages of spleen $\mathrm{T}$ regulatory cells (Tregs) (A) on sepsis-surviving mice in the

495 days indicated in the figure, as well as the representative flow cytometry plots (B) and the absolute

496 number of Tregs in the 15 days sepsis-surviving (Sepsis $15 \mathrm{~d})$ mice (C) addressed by flow cytometry. 
497 (D) Heat map of Foxp3 expression in spleen Tregs $\left(\mathrm{CD} 4^{+} \mathrm{CD} 25^{+}\right)$, conventional $\mathrm{T}$ cells (Tconv,

$498 \mathrm{CD}^{+} \mathrm{CD}^{-} 5^{-}$) and whole spleen tissue from Sepsis $15 \mathrm{~d}$ mice. Sepsis $15 \mathrm{~d}$ mice were inoculated with B16

499 melanoma cells $\left(5 \times 10^{4}\right.$ cells/mice) and, after 15 days, the tumor was removed and the intratumor

500 cells were evaluated by flow cytometry. (E) Representative flow cytometry plots and (F) frequency

501 of intratumoral Tregs. Frequency of $(\mathbf{G}) \mathrm{CD}^{+}$and $(\mathbf{H}) \mathrm{CD} 8^{+}$IFN $\gamma$-producing cells. The ratio

502 between Tregs cells and $\mathrm{CD}^{+}$or $\mathrm{CD}^{+}$IFN $\gamma$-producing cells (I) in the tumor microenvironment

503 from sepsis-surviving mice. Data are mean $\pm \mathrm{SD}, \mathrm{n}=6-8$ per group and are representative of $2-3$

504 independent experiments. * $p<0.5$ and $* * * * p<0.0001$ ( $\mathbf{A}$ and $\mathbf{I}, t$-test and $\mathbf{A}, \mathbf{F}-\mathbf{H}$ one way-

505 ANOVA, Bonferroni’s; D, Z-score normalized heat map).

FIGURE 3. Sepsis does not increase the M2-like macrophages profile in post-septic infant mice.

507 Infant and adult mice were intraperitoneally injected with $2 \times 10^{8}$ and $4 \times 10^{8}$ colony-forming units

508 (CFU) of cecum bacteria, respectively, and after six hours, the ertapenem antibiotic therapy (Abx, 15

$509 \mathrm{mg} / \mathrm{kg}$ for infant and $30 \mathrm{mg} / \mathrm{kg}$ for adults) was initiated and maintained for 3 days, via intraperitoneal

510 (i.p) twice a day. (A) Representative flow cytometry plots and frequency in the percentage of M2-like

511 macrophages $\left(\mathrm{F} 4 / 80^{+} \mathrm{CD} 206^{+}\right)$in the peritoneal exudates of 15 days sepsis-surviving (Sepsis $\left.15 \mathrm{~d}\right)$ mice.

512 (B) Live bacteria after killing assay of E. coli by peritoneal macrophages from Sepsis $15 \mathrm{~d}$ mice. $Y m 1$,

513 Mrcl and Argl relative expression in the days indicated in the figure or Sepsis $15 \mathrm{~d}$ mice in the (C)

514 peritoneal fluid exudates (D) total lung tissue, and (E) alveolar macrophages assessed by qPCR.

515 Infant and adult bone marrow-derived macrophages (BMDMs) were polarized in the presence of IL-4

$516(10 \mathrm{ng} / \mathrm{mL})$ for $48 \mathrm{~h}$. (F) Representative Flow cytometry plots and frequency in the percentage of

517 F4/80 ${ }^{+} \mathrm{CD} 206^{+}$macrophages. (G) Bone marrow-derived macrophages (M0) or M2-like polarized

518 macrophages (BMDM + IL-4, 48h) from infant or adult mice were co-cultured with infant or adult

519 spleen-isolated $\mathrm{CD}^{+} \mathrm{CD} 25^{-} \mathrm{T}$ cells in the presence of anti-eCD3 $(1 \mu \mathrm{g} / \mathrm{mL})$ and the Tregs

520 differentiation was addressed $72 \mathrm{~h}$ later by flow cytometry and shown as representative flow 
521 cytometry plots and frequency in the percentage of $\mathrm{CD}^{+} \mathrm{Foxp}^{+} \mathrm{T}$ cells (G). Data are mean $\pm \mathrm{SD}$,

$522 \mathrm{n}=4-6$, representative of two experiments, ${ }^{*} p<0.05, * * p<0.01, * * * p<0.001$ and $* * * * p<0.0001$ (one

523 way-ANOVA, Bonferroni's; C, $t$-test).

524 FIGURE 4. Sepsis does not increase the ILC2/IL-33 axis in sepsis-surviving infant mice. We

525 treated wild type mice (infant and adult) or infant ST2 deficient mice (ST2-/-) with recombinant IL-

52633 (rIL-33, 0,5 $\mu \mathrm{g} / \mathrm{kg}$ per 6 days), afterwards, the peritoneal lavage and the spleen were collected, and

527 their cell composition was evaluated by flow cytometry. Representative flow cytometry plots and

528 frequency of (A) M2-like macrophages calculated as the percentage of CD206 ${ }^{+}$cells among those

$529 \mathrm{~F} 4 / 80^{+}$in the peritoneal exudates and (B) spleen Tregs as Foxp3 ${ }^{+}$cells in the gate of those CD4 $4^{+}$

530 Infant and adult mice were intraperitoneally injected with $2 \times 10^{8}$ and $4 \times 10^{8}$ colony-forming units

531 (CFU) of cecum bacteria, respectively, and after six hours, the ertapenem antibiotic therapy (Abx, 15

$532 \mathrm{mg} / \mathrm{kg}$ for infant and $30 \mathrm{mg} / \mathrm{kg}$ for adults) was initiated and maintained for 3 days, via intraperitoneal

533 (i.p) twice a day. The following analyses, except the item K, were performed with the 15 days sepsis-

534 surviving $\left(\right.$ Sepsis $\left._{15 \mathrm{~d}}\right)$ mice. Concentration in picrogram per $\mathrm{mL}(\mathrm{pg} / \mathrm{mL})$ of (C) IL-10, (D) IL-4 and

535 (E) IL-33 in the lung homogenates. Il33 relative expression evaluated by qPCR in (F) lung tissue,

536 (G) lung whole Lin- cells (CD3e-Gr-1-CD11b-CD45R/B220-mTer-119) and H) alveolar epithelial

537 cells isolated from Sepsis ${ }_{15 d}$ infant mice (AECs, CD3e-Gr-1-CD11b-CD45R/B220-mTer-119-

$538 \mathrm{EpCAM}^{+}$). (I) total imprinting DNA methylation percentage performed in Lin-cells. (J)

539 Representative Flow cytometry plots and frequency in the percentage of lung ILC2s cells

540 (CD45 ${ }^{+}$Lin-Sca ${ }^{+}$cells). (K) Representative Flow cytometry plots and frequency in the percentage of

541 IL13-producing ILC2s cells (CD45 ${ }^{+}$in $\left.-\mathrm{Sca}-1^{+} \mathrm{IL}-13^{+}\right)$from infant and adult nä̈ve mice after phorbol

542 12-myristate 13-acetate/ionomycin stimulation (PMA/Ion). Data are mean $\pm \mathrm{SD}, \mathrm{n}=4-6$,

543 representative of two experiments, ${ }^{*} p<0.05, * * p<0.01, * * * p<0.001$ and $* * * * p<0.0001$ (A $-\mathbf{G}$, and 
$544 \mathbf{J}, \mathbf{K}$ one way-ANOVA, Bonferroni's; H, data are Z-score normalized heat map; I, data are presented

545 as \% of DNA methylated and no methylated).

546 FIGURE 5. Lack of Tregs/IL-33 expansion in sepsis-surviving pediatric patients. Blood samples

547 were collected from both pediatric and adult sepsis-surviving patients, as well as healthy volunteers,

548 after hospital discharge. (A) Representative flow cytometry plots (B) frequency in percentage (C)

549 and absolute number in $10^{5}$ cells per milliliter $\left(10^{5} / \mathrm{mL}\right)$ of CD4 ${ }^{+}$Foxp $^{+} \mathrm{T}$ cells. (D) Serum IL-33

550 levels in healthy and sepsis-surviving pediatric patients in picogram per $\mathrm{mL}(\mathrm{pg} / \mathrm{mL})$. Data are mean

$551 \pm \mathrm{SD}, * * p<0.01$ and $* * * * p<0.0001$ (Kruskal-Wallis unpaired test).

\section{Additional files}

FIGURE S1. Antibiotic-induced recovery from cecal bacteria peritonitis of infant and adult

mice and standardization of $P$. aeruginosa sublethal doses used as a second hit in our model.

555 Experimental setup of our two-hit models with $P$. aeruginosa and B16 tumor cells (A). Infant and

556 adult mice were intraperitoneally injected with $2 \times 10^{8}$ and $4 \times 10^{8}$ colony-forming units (CFU) of

557 cecum bacteria, respectively, and after six hours, the ertapenem antibiotic therapy (Abx, $15 \mathrm{mg} / \mathrm{kg}$ for

558 infant and $30 \mathrm{mg} / \mathrm{kg}$ for adults) was initiated and maintained for 3 days, via intraperitoneal (i.p) twice

559 a day. The survival (B) and the variation on the body weight (C) expressed in percentage were

560 periodically recorded, as indicated in the figures. In another set of experiments, we evaluated the

561 liver injury by measuring the glutamic-oxalacetic transaminase (GOT) levels expressed in units per

562 milliliter $(\mathrm{U} / \mathrm{mL})$ of plasma (D), and the blood bacterial count as the logarithm of CFU per milliliter

$563\left(\log _{10} \mathrm{CFU} / \mathrm{mL}\right)(\mathrm{E})$, in samples collected from sham animals or septic animals after $6 \mathrm{~h}$ and 1,7 and

56415 days after infection. Infant (F) and adult (G) naïve mice were infected with different doses of $P$.

565 aeruginosa $\left(4 \times 10^{6}, 2 \times 10^{6}\right.$ and $8 \times 10^{5} \mathrm{CFUs} /$ mice, intranasally), and the survival was recorded for 
56610 days and expressed as a percentage. Data are mean $\pm \mathrm{SD}, \mathrm{n}=6-8$ per group and are representative

567 of 2-3 independent experiments. $* p<0.5$ ( $t$-test).

570 Infant and adult mice were intraperitoneally injected with $2 \times 10^{8}$ and $4 \times 10^{8}$ colony-forming units

571 (CFU) of cecum bacteria, respectively, and after six hours, the ertapenem antibiotic therapy (Abx, 15

$572 \mathrm{mg} / \mathrm{kg}$ for infant and $30 \mathrm{mg} / \mathrm{kg}$ for adults) was initiated and maintained for 3 days, via intraperitoneal

573 (i.p) twice a day. Ex vivo proliferation capacity percentage of total spleen CD4 T cells after

574 polyclonal stimulation (anti-eCD3 and anti-CD28, $1 \mu \mathrm{g} / \mathrm{mL}$, respectively) from 15 days sepsis-

575 surviving $\left(\operatorname{Sepsis}_{15 \mathrm{~d}}\right)$ mice. Data are mean $\pm \mathrm{SD}, \mathrm{n}=6-8$ per group and are representative of 2-3

576 independent experiments. ${ }^{* *} p<0.01$ (one way-ANOVA, Bonferroni's).

FIGURE S3. Sepsis-surviving infant mice do not expand Tregs. Infant and adult mice were

579 intraperitoneally injected with $2 \times 10^{8}$ and $4 \times 10^{8}$ colony-forming units (CFU) of cecum bacteria,

580 respectively, and after six hours, the ertapenem antibiotic therapy $(\mathrm{Abx}, 15 \mathrm{mg} / \mathrm{kg}$ for infant and 30

$581 \mathrm{mg} / \mathrm{kg}$ for adults) was initiated and maintained for 3 days, via intraperitoneal (i.p) twice a day. The

58215 days sepsis surviving (Sepsis $15 \mathrm{~d}$ ) mice were then euthanized and the spleen was processed to the

583 flow cytometry analyses (A) Representative histogram of and total expression of Foxp3 in CD4 ${ }^{+}$cells

584 as mean fluorescence intensity (MFI). (B) Representative flow cytometry plot of Foxp3 expression in

$585 \mathrm{CD}^{+}$cells. Absolute number of induced (C) and natural (D) speen-derived T regulatory cells, iTregs

586 and nTregs, based on neuropilin 1 (Nrp1) expression on $\mathrm{CD}^{+} \mathrm{Foxp}^{+}$cells (natural (iTregs:

587 Foxp $3^{+} \mathrm{Nrp}^{-}$; nTregs: Foxp $3^{+} \mathrm{Nrp}^{+}$). Representative flow cytometry histograms (E) and frequency

588 (F) in the percentage of spleen $\mathrm{Ki}^{+} 7^{+}$cells on $\mathrm{CD}^{+} \mathrm{Foxp}^{+}$and $\mathrm{CD}^{+}$gates from Sepsis $15 \mathrm{~d}$ infant 
mice. Data are mean $\pm \mathrm{SD}, \mathrm{n}=6-8$ per group and are representative of 2-3 independent experiments. *

$p<0.05 * * p<0.01$ and $* * * p<0.001$ (A, C and D, one way-ANOVA, Bonferroni'; $\mathbf{F}, t$-test).

FIGURE S4. Tregs in vitro differentiation is independent of age. (A) In vitro Tregs differentiation

from adult and infant DEREG mice (Foxp3-DTR/EGFP) after stimulation with TGF- $\beta 1$ (1 and 3

$\mathrm{ng} / \mathrm{mL}$ ) for $72 \mathrm{~h}, 37^{\circ} \mathrm{C} 5 \% \mathrm{CO}_{2}$. (A) Representative flow cytometry plots and frequency in the

percentage of $\mathrm{CD}^{+}{ }^{+}$Foxp3eGFP ${ }^{+} \mathrm{T}$ cells (Tregs). (B) $\mathrm{CD}^{+}{ }^{+}$Foxp3eGFP- $\mathrm{T}$ cells from infant and adult

mice were differentiated in vitro and the expression of Tregs hallmark genes were assessed by qPCR.

(C) Representative flow cytometry plots and frequency of CD25 negative (CD25), CD25 intermediate

$\left(\mathrm{CD} 25^{\text {int }}\right)$ and $\mathrm{CD} 25$ high $\left(\mathrm{CD} 25^{\text {hi }}\right)$ on $\mathrm{CD}^{+} \mathrm{T}$ cells after polyclonal stimulation (anti-eCD3 and anti-

CD28, 1 $\mu \mathrm{g} / \mathrm{mL}$ ). (D) Representative immunoblots of p-Smad2/3, Smad2/3, pCREB and CREB on

per group and are representative of 2-3 independent experiments.

FIGURE S5. Bone marrow-derived macrophages from infant and adult mice are similarly able

to polarize to M2-like macrophages. Bone marrow-derived macrophages (BMDMs) obtained from

infant and adult mice were polarized in the presence of IL-4 (10ng/mL) for $48 \mathrm{~h}$. (A) Representative

macrophages hallmark genes after in vitro polarization in the time point indicated assessed by qPCR.

(C) CCL22 and IGF-1 levels were expressed in picograms per $\mathrm{mL}(\mathrm{pg} / \mathrm{mL})$ in the supernatant of the 
612 FIGURE S6. Recombinant IL-33 boosted the expansion of ST2 ${ }^{+}$Tregs. We treated wild type mice

613 (infant and adult) or infant ST2 deficient mice (ST2-/-) with recombinant IL-33 (rIL-33, 0,5 $\mu \mathrm{g} / \mathrm{kg}$ per

6146 days) and the spleens were collected, and their cell composition was evaluated by flow cytometry.

615 Frequency and representative flow cytometry plots spleen Tregs as Foxp $3^{+}$cells in the gate of those

$616 \mathrm{CD}^{+}$. Percentage and representative flow cytometry plots of spleen Tregs $\mathrm{ST} 2^{+}\left(\mathrm{Foxp}^{+} \mathrm{ST} 2^{+}\right.$cells).

617 Data are mean $\pm \mathrm{SD}, \mathrm{n}=3-5$ per group. ${ }^{*} \mathrm{p}<0$. (Two way-ANOVA, Tukey).

FIGURE S7. Sepsis does not increase the ILC2/IL-33 axis in sepsis-surviving infant mice. Infant

and adult mice were intraperitoneally injected with $2 \times 10^{8}$ and $4 \times 10^{8}$ colony-forming units (CFU) of

621 cecum bacteria, respectively, and after six hours, the ertapenem antibiotic therapy (Abx, $15 \mathrm{mg} / \mathrm{kg}$ for

622 infant and $30 \mathrm{mg} / \mathrm{kg}$ for adults) was initiated and maintained for 3 days, via intraperitoneal (i.p) twice

623 a day. The 15 days sepsis surviving (Sepsis15d) mice were then euthanized and the bronchoalveolar

624 lavage (BAL) and the lung tissue were collected for further analysis. (A) IL-33 and (B) sST2 levels

625 in picogram per $\mathrm{mL}(\mathrm{pg} / \mathrm{mL})$ in the BAL. (C) Sorting strategy flow cytometry plots of lung alveolar 626 epithelial cells (AECs). (D) Absolute number of lungs ILC2s cells (CD45 Lin $^{-} \mathrm{Sca} 1^{+}$cells) expressed

627 in cells $\times 10^{5}\left(\times 10^{5}\right)$, mean fluorescence intensity $\times 10^{3}$ (MFI x 10 $)$ and Scal expression in

628 percentage on $\mathrm{CD}^{4} 5^{+} \operatorname{Lin}^{-}$cells. Data are mean $\pm \mathrm{SD}, \mathrm{n}=4-6$, representative of two experiments, $629 * p<0.05$ (one way-ANOVA, Bonferroni’s).

631 FIGURE S8. Tregs suppression activity is preserved in sepsis-surviving pediatric patients.

632 Blood samples were collected from sepsis-surviving pediatric patients, and healthy volunteers, after

633 hospital discharge. Representative histogram of $\mathrm{T}$ effector cells $\left(\mathrm{CD}^{+} \mathrm{CD}^{-} 5^{-} \mathrm{CFSE}^{+}\right)$proliferation in

634 the presence of a serially diluted concentration of Tregs $72 \mathrm{~h}$ after polyclonal stimulation $(1 \mu \mathrm{g} / \mathrm{mL})$. 
636 TABLE S1. Demographic and clinical characteristics of the sepsis-surviving patients. SOFA,

637 Sequential Organ Failure Assessment. APACHE, Acute Physiology and Chronic Health Evaluation.

638 PRISM, Pediatric Risk of Mortality. PELOD, Pediatric Logistic Organ Dysfunction. PRISM,

639 Pediatric Risk of Mortality.

640

\section{$641 \quad$ References}

642 1. Singer M, et al. The Third International Consensus Definitions for Sepsis and Septic Shock 643 (Sepsis-3). JAMA 315, 801-810 (2016).

644

2. Muenzer JT, et al. Characterization and modulation of the immunosuppressive phase of sepsis. Infect Immun 78, 1582-1592 (2010).

3. Meakins JL, et al. Delayed hypersensitivity: indicator of acquired failure of host defenses in sepsis and trauma. Annals of surgery 186, 241-250 (1977).

650

651

652

653

4. Wang T, Derhovanessian A, De Cruz S, Belperio JA, Deng JC, Hoo GS. Subsequent infections in survivors of sepsis: epidemiology and outcomes. J Intensive Care Med 29, 87-95 (2014).

654

5. Hotchkiss RS, Monneret G, Payen D. Sepsis-induced immunosuppression: from cellular dysfunctions to immunotherapy. Nat Rev Immunol 13, 862-874 (2013).

6. Otto GP, et al. The late phase of sepsis is characterized by an increased microbiological

661 7. Hall MW, Gavrilin MA, Knatz NL, Duncan MD, Fernandez SA, Wewers MD. Monocyte 
665 8. Hall MW, et al. Innate immune function and mortality in critically ill children with influenza:

666 a multicenter study. Crit Care Med 41, 224-236 (2013).

667

668 9. Morrison AL, Gillis J, O'Connell AJ, Schell DN, Dossetor DR, Mellis C. Quality of life of 669 survivors of pediatric intensive care. Pediatr Crit Care Med 3, 1-5 (2002).

670

671

10. Vincent JL, Opal SM, Marshall JC, Tracey KJ. Sepsis definitions: time for change. Lancet

11. Steinhauser ML, Hogaboam CM, Kunkel SL, Lukacs NW, Strieter RM, Standiford TJ. IL-10 is a major mediator of sepsis-induced impairment in lung antibacterial host defense. $J$ Immunol 162, 392-399 (1999).

12. Boomer JS, et al. Immunosuppression in patients who die of sepsis and multiple organ failure. JAMA 306, 2594-2605 (2011).

13. Roquilly A, et al. Alveolar macrophages are epigenetically altered after inflammation, leading to long-term lung immunoparalysis. Nat Immunol 21, 636-648 (2020).

14. Cross D, Drury R, Hill J, Pollard AJ. Epigenetics in Sepsis: Understanding Its Role in 1363 (2019).

15. Nascimento DC, et al. Role of regulatory $\mathrm{T}$ cells in long-term immune dysfunction associated with severe sepsis. Crit Care Med 38, 1718-1725 (2010).

693

17. Nascimento DC, et al. IL-33 contributes to sepsis-induced long-term immunosuppression by

16. Cavassani KA, et al. The post sepsis-induced expansion and enhanced function of regulatory $\mathrm{T}$ cells create an environment to potentiate tumor growth. Blood 115, 4403-4411 (2010).

18. Nascimento DC, et al. Sepsis expands a CD39(+) plasmablast population that promotes immunosuppression via adenosine-mediated inhibition of macrophage antimicrobial activity. Immunity 54, 2024-2041 e2028 (2021). 
19. Venet $\mathrm{F}$, et al. Increased circulating regulatory $\mathrm{T}$ cells $(\mathrm{CD} 4(+) \mathrm{CD} 25(+) \mathrm{CD} 127(-))$ contribute to lymphocyte anergy in septic shock patients. Intensive Care Med 35, 678-686 (2009).

20. Liew FY, Pitman NI, McInnes IB. Disease-associated functions of IL-33: the new kid in the IL-1 family. Nat Rev Immunol 10, 103-110 (2010).

21. Smith DE. IL-33: a tissue derived cytokine pathway involved in allergic inflammation and 709 asthma. Clin Exp Allergy 40, 200-208 (2010).

22. Liew FY. IL-33: a Janus cytokine. Ann Rheum Dis 71 Suppl 2, i101-104 (2012).

712

23. Heyen L, et al. Lung epithelium is the major source of IL-33 and is regulated by IL-33dependent and IL-33-independent mechanisms in pulmonary cryptococcosis. Pathog Dis 74, (2016).

24. Byers DE, et al. Long-term IL-33-producing epithelial progenitor cells in chronic obstructive lung disease. J Clin Invest 123, 3967-3982 (2013).

25. Mirchandani AS, Salmond RJ, Liew FY. Interleukin-33 and the function of innate lymphoid cells. Trends Immunol 33, 389-396 (2012).

26. Schmitz J, et al. IL-33, an interleukin-1-like cytokine that signals via the IL-1 receptor-related

27. Kurowska-Stolarska M, et al. IL-33 amplifies the polarization of alternatively activated macrophages that contribute to airway inflammation. J Immunol 183, 6469-6477 (2009).

28. Levy MM, et al. 2001 SCCM/ESICM/ACCP/ATS/SIS International Sepsis Definitions

29. Leteurtre S, et al. Validation of the paediatric logistic organ dysfunction (PELOD) score: prospective, observational, multicentre study. Lancet 362, 192-197 (2003). 
30. Pollack MM, Ruttimann UE, Getson PR. Pediatric risk of mortality (PRISM) score. Crit Care Med 16, 1110-1116 (1988).

31. Clark JD, Gebhart GF, Gonder JC, Keeling ME, Kohn DF. Special Report: The 1996 Guide

32. Godshall CJ, Scott MJ, Peyton JC, Gardner SA, Cheadle WG. Genetic background

33. Colon DF, et al. Neutrophil extracellular traps (NETs) exacerbate severity of infant sepsis.

34. Pena $\mathrm{C}$, et al. Carbapenem-resistant Pseudomonas aeruginosa: factors influencing multidrug(2009).

35. Juan C, Pena C, Oliver A. Host and Pathogen Biomarkers for Severe Pseudomonas

36. Mota JM, et al. Post-Sepsis State Induces Tumor-Associated Macrophage Accumulation

37. Benjamim CF, Hogaboam CM, Lukacs NW, Kunkel SL. Septic mice are susceptible to

pulmonary aspergillosis. Am J Pathol 163, 2605-2617 (2003).

38. Roquilly A, et al. Local Modulation of Antigen-Presenting Cell Development after Resolution of Pneumonia Induces Long-Term Susceptibility to Secondary Infections. Immunity 47, 135147 e135 (2017).

39. Song A, Song J, Tang X, Croft M. Cooperation between CD4 and CD8 T cells for anti-tumor 
40. Beatty G, Paterson Y. IFN-gamma-dependent inhibition of tumor angiogenesis by tumorinfiltrating CD4+ $\mathrm{T}$ cells requires tumor responsiveness to IFN-gamma. J Immunol 166, 2276-2282 (2001).

41. Casares $\mathrm{N}$, et al. $\mathrm{CD} 4+/ \mathrm{CD} 25+$ regulatory cells inhibit activation of tumor-primed CD4+ $\mathrm{T}$ cells with IFN-gamma-dependent antiangiogenic activity, as well as long-lasting tumor immunity elicited by peptide vaccination. J Immunol 171, 5931-5939 (2003).

42. Kim R, Emi M, Tanabe K, Arihiro K. Tumor-driven evolution of immunosuppressive networks during malignant progression. Cancer Res 66, 5527-5536 (2006).

43. Tone Y, Furuuchi K, Kojima Y, Tykocinski ML, Greene MI, Tone M. Smad3 and NFAT cooperate to induce Foxp3 expression through its enhancer. Nat Immunol 9, 194-202 (2008).

44. Ogawa C, Tone Y, Tsuda M, Peter C, Waldmann H, Tone M. TGF-beta-mediated Foxp3 gene expression is cooperatively regulated by Stat5, Creb, and AP-1 through CNS2. J Immunol 192, 475-483 (2014).

45. Cao Q, et al. IL-10/TGF-beta-modified macrophages induce regulatory $\mathrm{T}$ cells and protect against adriamycin nephrosis. J Am Soc Nephrol 21, 933-942 (2010).

46. Watanabe N, Suzuki Y, Inokuchi S, Inoue S. Sepsis induces incomplete M2 phenotype polarization in peritoneal exudate cells in mice. J Intensive Care 4, 6 (2016).

47. Sun W, et al. A positive-feedback loop between tumour infiltrating activated Treg cells and type 2-skewed macrophages is essential for progression of laryngeal squamous cell carcinoma. Br J Cancer 117, 1631-1643 (2017).

48. Spadaro O, et al. IGF1 Shapes Macrophage Activation in Response to Immunometabolic Challenge. Cell Rep 19, 225-234 (2017).

49. Ishida T, Ueda R. CCR4 as a novel molecular target for immunotherapy of cancer. Cancer Sci 97, 1139-1146 (2006).

50. Cayrol C, Girard JP. Interleukin-33 (IL-33): A nuclear cytokine from the IL-1 family. Immunological reviews 281, 154-168 (2018). 
805 51. Polumuri SK, et al. Transcriptional regulation of murine IL-33 by TLR and non-TLR agonists. J Immunol 189, 50-60 (2012).

807

808 52. Zhang F, Tossberg JT, Spurlock CF, Yao SY, Aune TM, Sriram S. Expression of IL-33 and its epigenetic regulation in Multiple Sclerosis. Ann Clin Transl Neurol 1, 307-318 (2014).

810

811 53. Larouche M, et al. Methylation profiles of IL33 and CCL26 in bronchial epithelial cells are associated with asthma. Epigenomics 10, 1555-1568 (2018).

813

814

815

816

817

818

819

820

821

822

823 


\section{Figures}

827 Figure 1

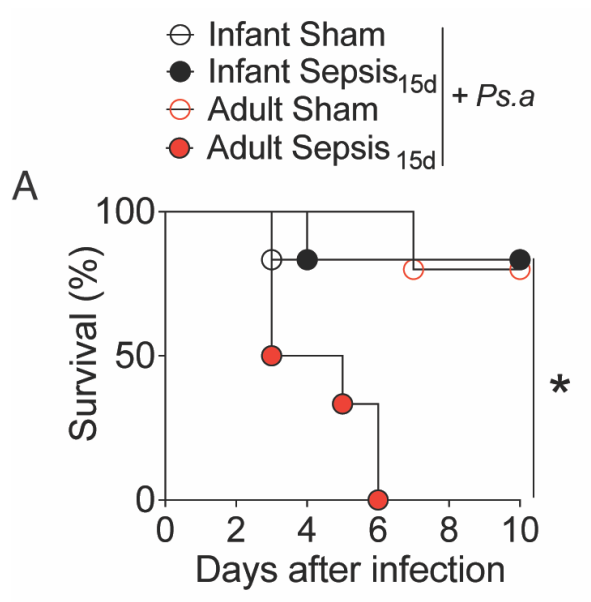

D

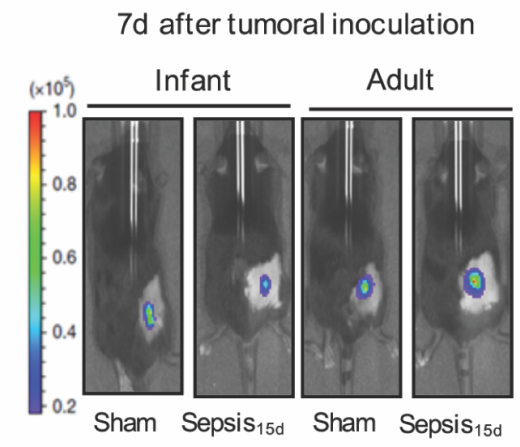

B

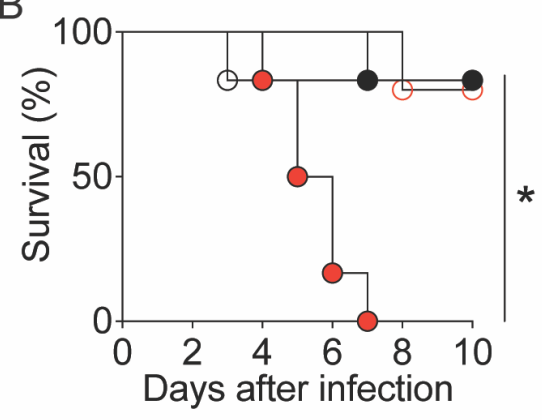

E

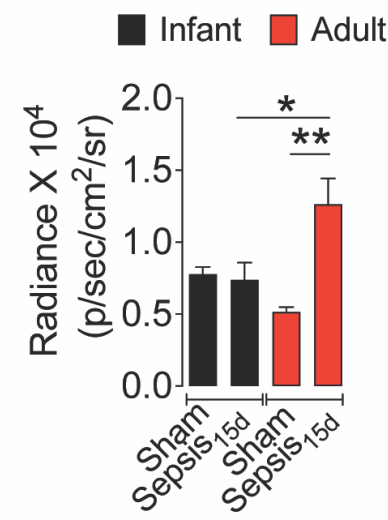

$\ominus$ Infant Sham

- Infant Sepsis 30

$\ominus$ Adult Sham ${ }^{30 d}+$ Ps.a

- Adult Sepsis ${ }_{30 d}$

Days after infection

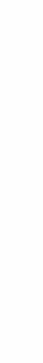

C
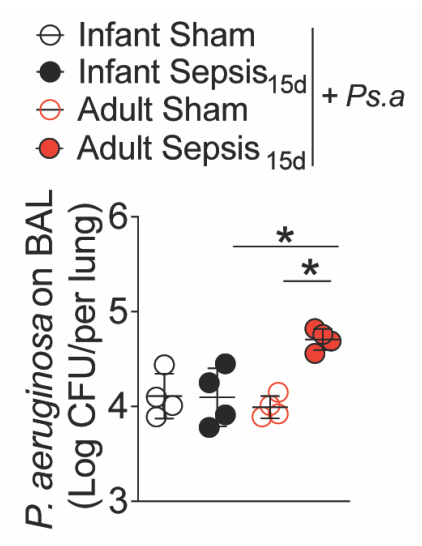

F $\quad \begin{aligned} & \text { Infant Sham } \\ & - \text { Infant Sepsis }_{15 d}\end{aligned}$

$\ominus$ Adult Sham

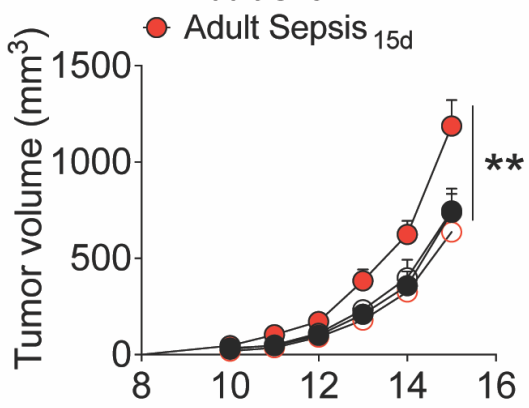

Days after tumor inoculation 
bioRxiv preprint doi: https://doi.org/10.1101/2022.01.15.476447; this version posted January 16,2022 . The copyright holder for this preprint (which was not certified by peer review) is the author/funder, who has granted bioRxiv a license to display the preprint in perpetuity. It is made available under aCC-BY-NC-ND 4.0 International license.

\section{$838 \quad$ Figure 2}

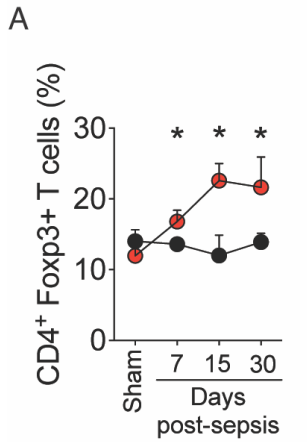

E

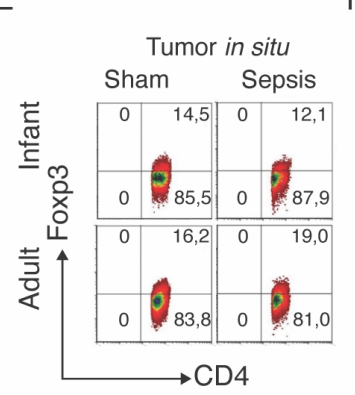

B

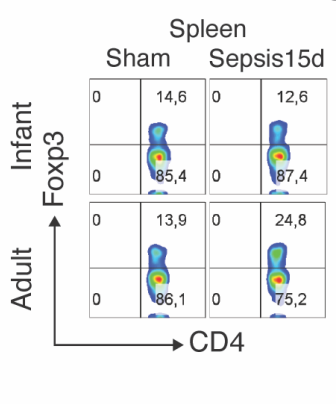

F

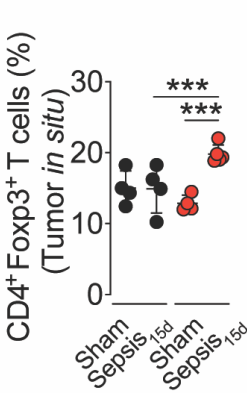

C

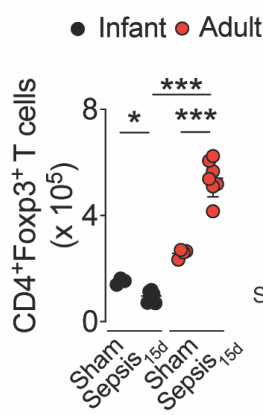

D

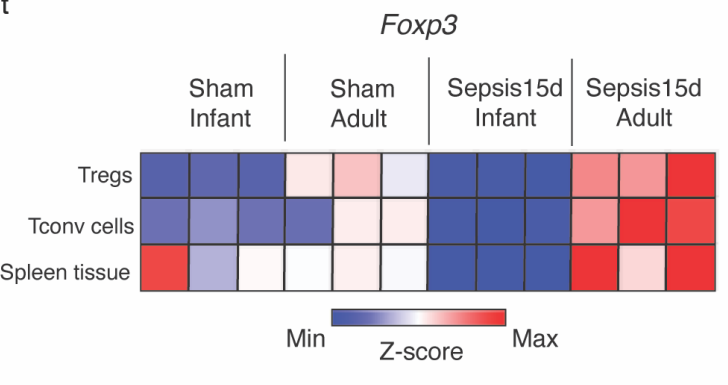

G

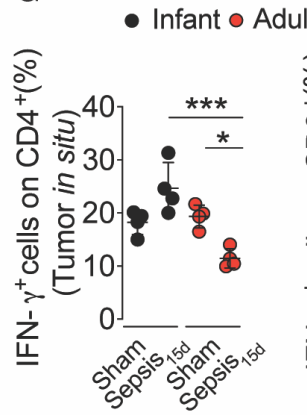

$\mathrm{H}$

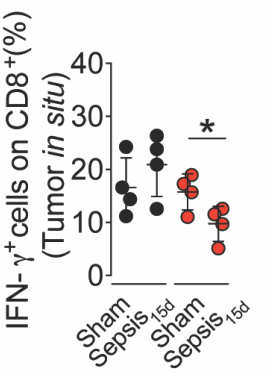

I
Sepsis-surviving mice

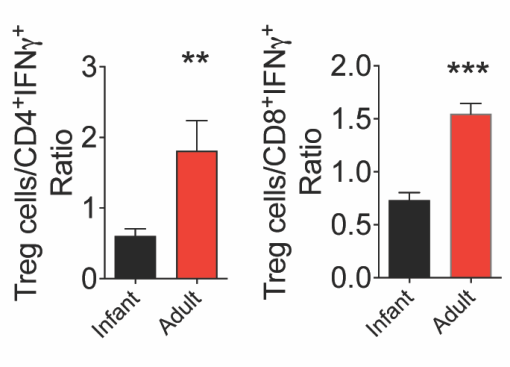

839

840

841

842

843

844

845

846

847

848

849

850

851

852 
bioRxiv preprint doi: https://doi.org/10.1101/2022.01.15.476447; this version posted January 16, 2022. The copyright holder for this preprint (which was not certified by peer review) is the author/funder, who has granted bioRxiv a license to display the preprint in perpetuity. It is made available under aCC-BY-NC-ND 4.0 International license.

\section{$853 \quad$ Figure 3}

A

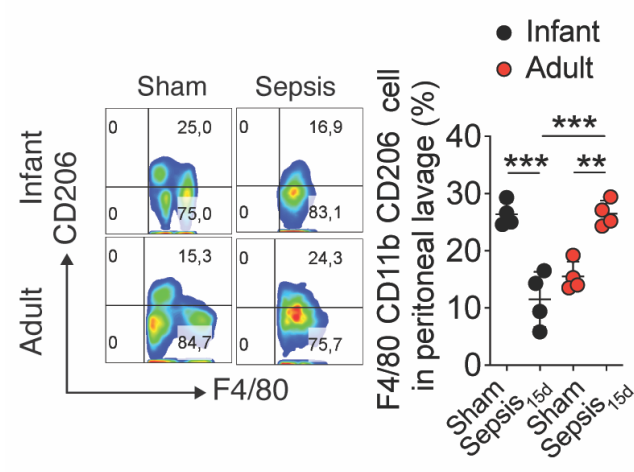

B

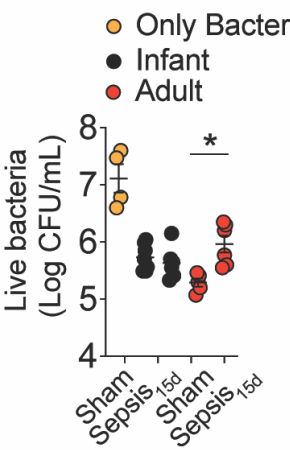

C

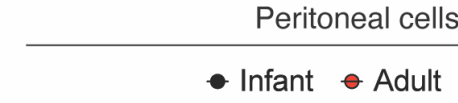

D

Total lung tissue

- Infant $\square$ Adult

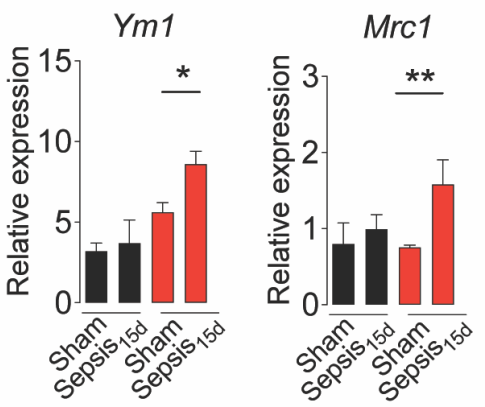

$\mathrm{F}$

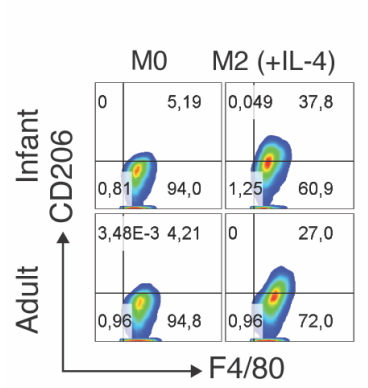

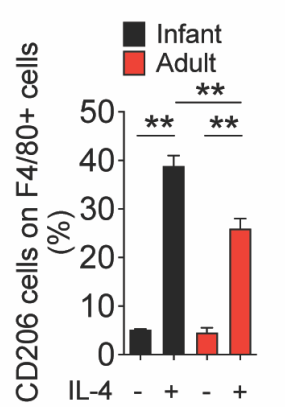

$\operatorname{Arg} 1$

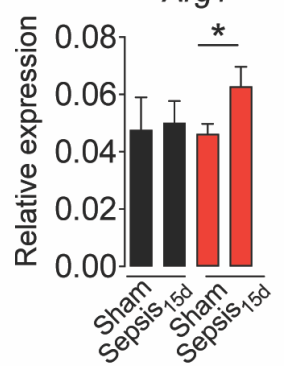

$\mathrm{G}$

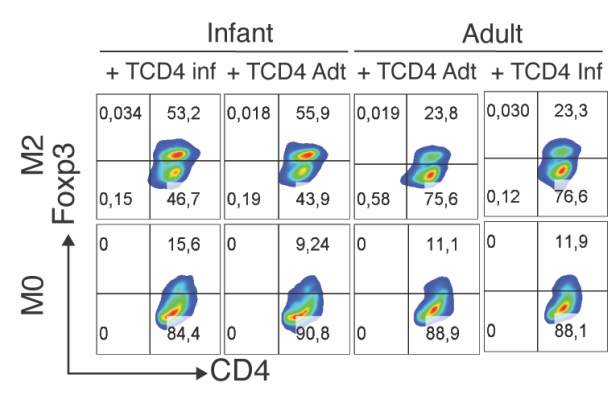

$\mathrm{E}$

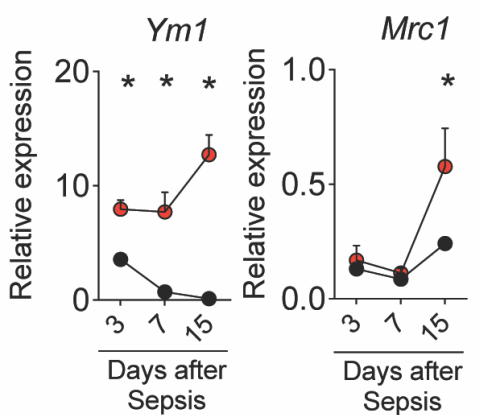

Alveolar macrophages

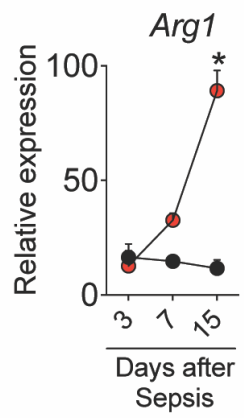

- Infant $\quad$ Adult
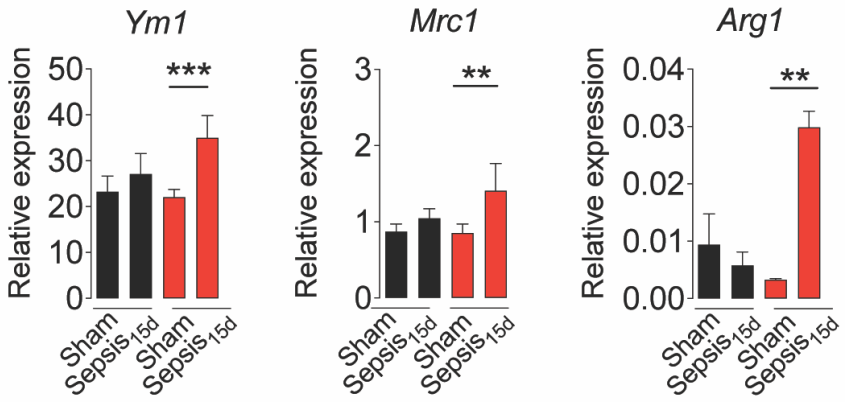

855 
bioRxiv preprint doi: https://doi.org/10.1101/2022 01.15.476447; this version posted January 16, 2022. The copyright holder for this preprint (which was not certified by peer review) is the author/funder, who has granted bioRxiv a license to display the preprint in perpetuity. It is made available under aCC-BY-NC-ND 4.0 International license.

\section{$861 \quad$ Figure 4}

A

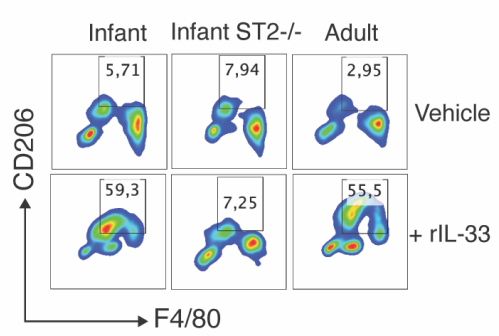

- Infant o Adult

C
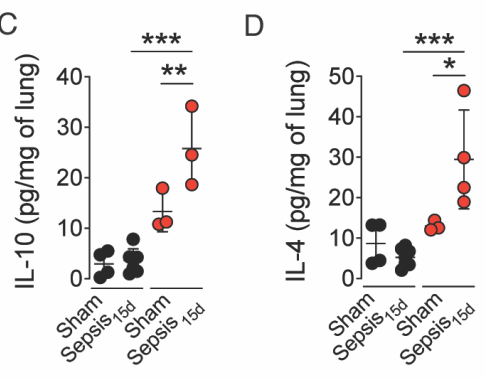

E

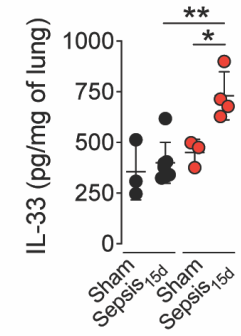

J

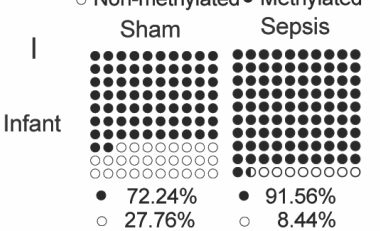

Adult
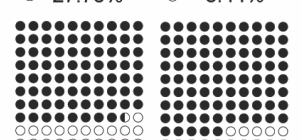

$\begin{array}{ccc}0000000000 & 0000000000 \\ -78.57 \% & \bullet & 85.14 \%\end{array}$

$\begin{array}{ll}78.57 \% & \circ \\ 21.43 \% & -14.86 \%\end{array}$

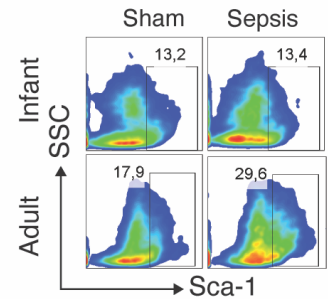

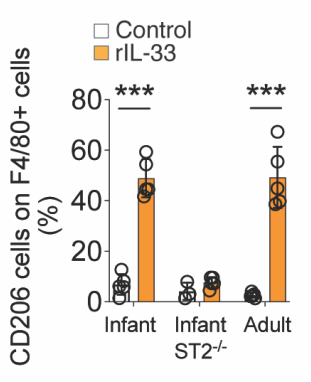

B
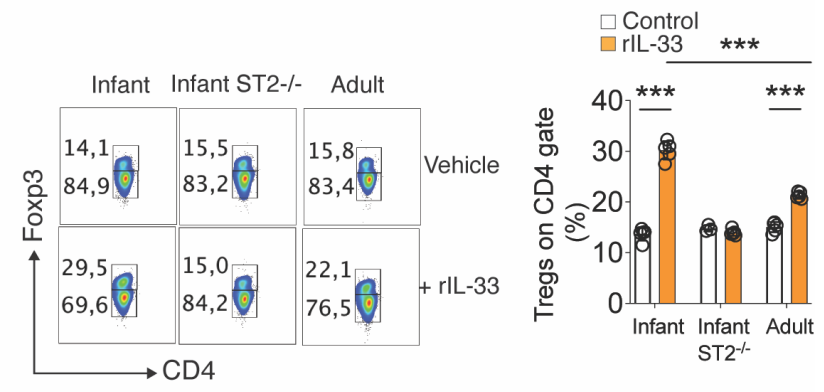

- Infant ○ Adult

F Lung tissue

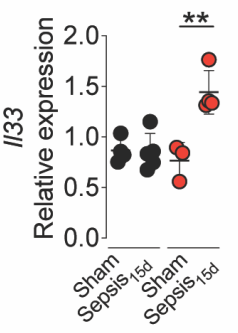

G Lung whole Lin- cells

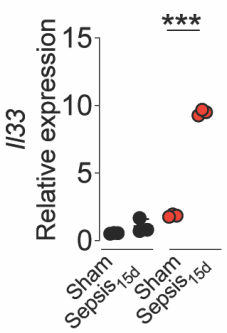

H

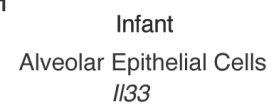
I/33

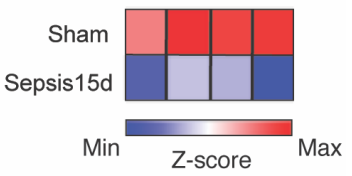

- Infant ○ Adult

- Infant o Adult

K
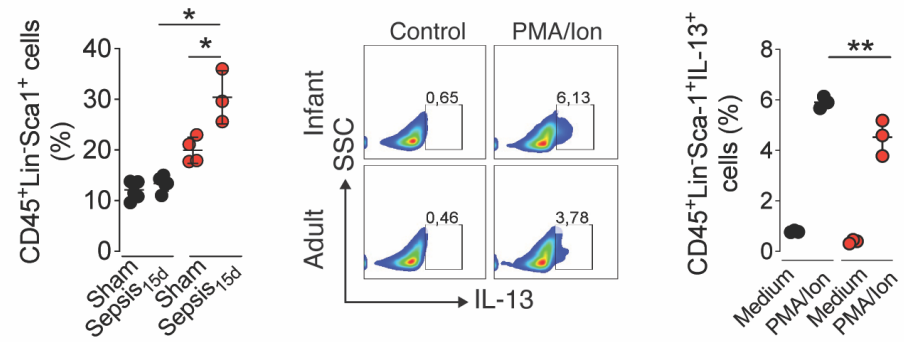

863

864

865

866

867 


\section{Figure 5}

A

870

871

872

873

874

875

876

877

878

879

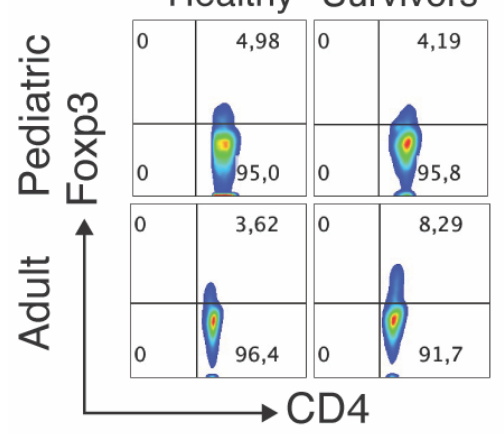

B

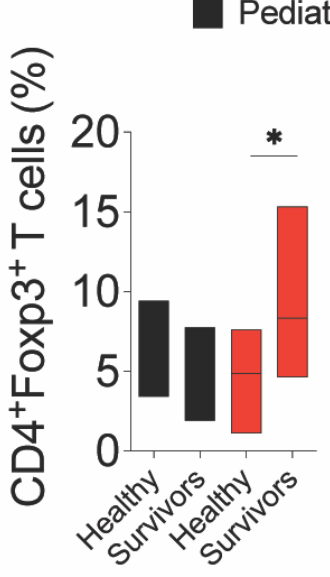

C

Adults

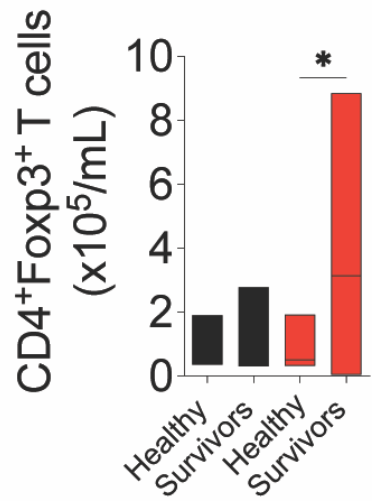

D
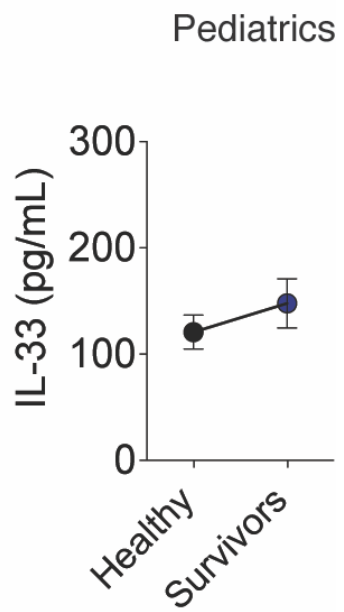